\title{
SELEÇÃO E ENXERTIA DE GENÓTIPOS DE ZEYHERIA TUBERCULOSA (VELL.) BUREAU EX VERL (IPÊ-FELPUDO) AVALIADOS EM TESTE DE PROGÊNIES
}

\author{
AUTOR: MARLON DOS SANTOS PEREIRA BIRINDIBA GARUZZO \\ CO-AUTOR/ORIENTADOR: ANDREI CAIQUE PIRES NUNES
}

Resumo: A espécie Z. tuberculosa é nativa do Brasil e apresenta potencial silvicultural para a indústria madeireira. Diante disso, com o melhoramento genético, indivíduos desta espécie poderão ser destinados para plantios silviculturais em larga escala. Este estudo objetivou: (a) Caracterizar a variabilidade genética de um teste de progênies/procedências de Z. tuberculosa (b) selecionar matrizes, indivíduos potenciais genitores e potenciais clones de Z. tuberculosa, por meio de análise estatístico-genética, (c) avaliar a progressão genética futura das populações de melhoramento com a simulação de cruzamento aberto dos dez melhores indivíduos potenciais genitores e (d) estudar a viabilidade de enxertia desses indivíduos selecionados. A partir da avaliação do teste de progênies/procedência para o parâmetro herdabilidade ( $\mathrm{h} 2 \mathrm{a})$ foram obtidos os valores de fuste $(0,01)$, forma $(0,11)$, diâmetro a altura do peito $(\operatorname{DAP}, \mathrm{cm})(0,26)$ e galhos $(0,24)$. Estas estimativas comparadas a outras espécies nativas revelam que a população apresenta variabilidade para o melhoramento genético em relação ao DAP, forma e galhos, viabilizando os ganhos genéticos que poderão ser obtidos com futuras avaliações. A seleção de famílias computou 30 famílias, entre essas foram selecionadas as dez melhores. Essas apresentaram ganhos genéticos que variam entre $6,29 \%$ a $32,34 \%$. Os ganhos com seleção dos potenciais genitores revelam estimativas que variam de $7,72 \%$ a $33,98 \%$ para os dez potenciais genitores de famílias diferentes com efeito genético positivo. Os ganhos estimados para os 15 melhores clones revelam valores que variaram de $39,12 \%$ a $75,99 \%$. O primeiro classificado, árvore 167 (75,99\%) é um importante indivíduo a ser indicado para a propagação vegetativa. A produção média estimada da nova geração de árvores revela valores de DAP, que variam entre 8,95 a 9,97 cm, resultados positivos e superiores à média de DAP da população original $(7,83 \mathrm{~cm})$. Os ganhos genéticos com a coleta de sementes em cada um dos dez genitores apresentaram resultados entre $14,11 \%$ a $27,24 \%$. A enxertia de ipê-felpudo é possível de ser realizada com a técnica de propagação vegetativa do tipo garfagem de topo. A taxa de pegamento variou de $20 \%$ a $80 \%$ por genótipo e na média foi de $51 \%$. Nesse contexto, os resultados indicam êxito na seleção estatística-genética dos genótipos e possibilidade de propagação vegetativa da espécie, o que garante a viabilidade da condução do programa de melhoramento genético da espécie.

Palavras-chave: Melhoramento genético, Árvore nativa, Análise genética, Silvicultura. 